\title{
Noncirrhotic Portal Hypertension
}

\author{
Harshal Rajekar*, Rakesh K Vasishta**, Yogesh K Chawla ${ }^{\dagger}$, Radha K Dhiman ${ }^{\dagger}$ \\ Departments of ${ }^{*}$ General Surgery, ${ }^{*}$ Histopathology, and ${ }^{\dagger}$ Hepatology, Postgraduate Institute of \\ Medical Education and Research, Chandigarh - 160012, India
}

\begin{abstract}
Portal hypertension is characterized by an increase in portal pressure $(>10 \mathrm{mmHg})$ and could be a result of cirrhosis of the liver or of noncirrhotic diseases. When portal hypertension occurs in the absence of liver cirrhosis, noncirrhotic portal hypertension (NCPH) must be considered. The prognosis of this disease is much better than that of cirrhosis. Noncirrhotic diseases are the common cause of portal hypertension in developing countries, especially in Asia. NCPH is a heterogeneous group of diseases that is due to intrahepatic or extrahepatic etiologies. In general, the lesions in NCPH are vascular in nature and can be classified based on the site of resistance to blood flow. In most cases, these disorders can be explained by endothelial cell lesions, intimal thickening, thrombotic obliterations, or scarring of the intrahepatic portal or hepatic venous circulation. Many different conditions can determine NCPH through the association of these various lesions in various degrees. Many clinical manifestations of NCPH result from the secondary effects of portal hypertension. Patients with NCPH present with upper gastrointestinal bleeding, splenomegaly, ascites after gastrointestinal bleeding, features of hypersplenism, growth retardation, and jaundice due to portal hypertensive biliopathy. Other sequelae include hyperdynamic circulation, pulmonary complications, and other effects of portosystemic collateral circulation like portosystemic encephalopathy. At present, pharmacologic and endoscopic treatments are the treatments of choice for portal hypertension. The therapy of all disorders causing NCPH involves the reduction of portal pressure by pharmacotherapy or portosystemic shunting, apart from prevention and treatment of complications of portal hypertension. (J CLIN EXP HEPATOL 2011;1:94-108)
\end{abstract}

$\mathrm{P}$ ortal hypertension is defined as a pathological increase in the pressure of the portal venous system. Cirrhosis is the most common cause of portal hypertension but portal hypertension can also be present

Keywords: Budd-Chiari syndrome, congenital hepatic fibrosis, extrahepatic portal venous obstruction, nodular regenerative hyperplasia, noncirrhotic intrahepatic portal hypertension, portal vein thrombosis, portosystemic shunting, schistosomiasis, veno-occlusive disease

Received: 09.09.2011; Accepted: 13.09.2011

Address for correspondence: Radha K Dhiman, Professor, Department of Hepatology, Postgraduate Institute of Medical Education and Research, Chandigarh - 160012, India

E-mail: rkpsdhiman@hotmail.com

Abbreviations: ADPKD: autosomal-dominant polycystic kidney disease; ARPKD: autosomal-recessive polycystic kidney disease; BCS: Budd-Chiari syndrome; CHF: congenital hepatic fibrosis; CTGF: connective tissue growth factor; DSRS: distal splenorenal Shunt; EHPVO: extrahepatic portal vein obstruction; EHPVO: extrahepatic portal vein obstruction; ERCP: endoscopic retrograde cholangio pancreatography; EST: endoscopic sclerotherapy; EVL: endoscopic variceal ligation; FHF: fulminant hepatic failure; GI: Gastrointestinal; GVHD: graft versus cells host disease; HLA: human lymphocyte antigen; HVPG: hepatic vanous pressure gradient; IPH: idiopathic portal hypertension; IVC: inferior vena cava; MRCP: magnetic resonance cholangio pancreatography; NCPF: noncirrhotic portal hypertension; NCPH: noncirrhotic portal hypertension; NRH: nodular regenerative hyperplasia; PVT: portal vein thrombosis; SCT: stem-cell transplantation; TIPS: transjugular intrahepatic portosystemic shunt placement; TIPSS: transjugular intrahepatic portosystemic shunt; VOD: veno-occlusive disease

doi: 10.1016/S0973-6883(11)60128-X in the absence of cirrhosis, a condition referred to as "noncirrhotic portal hypertension (NCPH)." We aim to review the principal causes of $\mathrm{NCPH}$ in this article.

Cirrhosis is by far the commonest cause of portal hypertension accounting for $>90 \%$ cases in the West and $>80 \%$ in Asia and Africa. ${ }^{1} \mathrm{NCPH}$, due to intrahepatic or extrahepatic etiologies, is a fairly common cause of portal hypertension in India. NCPH can be classified based on the site of resistance to blood flow as "prehepatic," "hepatic," and "posthepatic." The "hepatic" causes of NCPH can be subdivided into "presinusoidal," "sinusoidal," and "postsinusoidal" (Table 1).

NCPF was first described in 1889 by Banti ${ }^{2}$ as a cause of massive splenomegaly with anemia and upper GI bleeding, and then again in 1940 by Ravenna as a cause of massive splenomegaly without any gross liver pathology. ${ }^{3}$ It has been variously described as hepatoportal sclerosis, ${ }^{4}$ benign intrahepatic portal hypertension, ${ }^{5}$ and idiopathic presinusoidal portal hypertension. ${ }^{6}$ Mikkelsen et $\mathrm{al}^{4}$ identified sclerosis of the portal vein and its radicals in patients with portal hypertension without cirrhosis; they called this condition "hepatoportal sclerosis." Boyer et $\mathrm{al}^{7}$ described the term "idiopathic portal hypertension" (IPH), and showed a more favorable prognosis than cirrhosis. The term NCPF was used first by Basu et $\mathrm{al}^{8}$ in 1967 and subsequently was endorsed by the Indian Council of Medical Research. This condition was reported simultaneously from Japan, where 
Table 1 Causes of noncirrhotic portal hypertension.

\begin{tabular}{l}
\hline Prehepatic \\
Extrahepatic portal vein obstruction (EHPVO) \\
Congenital stenosis of the portal vein \\
Extrinsic compression of the portal vein \\
Splenic vein thrombosis \\
Arteriovenous fistulae \\
Intrahepatic \\
Idiopathic portal hypertension (IPH)/noncirrhotic portal fibrosis \\
(NCPF) \\
Nodular regenerative hyperplasia \\
Congenital hepatic fibrosis \\
Granulomatous diseases (schistosomiasis, sarcoidosis, \\
tuberculosis, primary biliary cirrhosis) \\
Peliosis hepatis \\
Polycystic disease \\
Hypervitaminosis A \\
Arsenic, copper sulfate, vinyl chloride monomer poisoning \\
Amyloidosis \\
Rendu-Osler-Weber syndrome \\
Acute fatty liver of pregnancy \\
Severe acute viral and alcoholic hepatitis \\
Chronic hepatitis \\
Veno-occlusive disease \\
Posthepatic \\
Hepatic vein thrombosis (Budd-Chiari syndrome) \\
Congenital malformations and thrombosis of the inferior vena cava \\
Constrictive pericarditis, tricuspid valve diseases \\
\hline
\end{tabular}

a condition similar to NCPF is termed idiopathic portal fibrosis (IPH). ${ }^{9,10}$

\section{Epidemiology}

Noncirrhotic portal hypertension/idiopathic portal hypertension is seen all over the world, though it is far more common in the developing world ${ }^{11}$ and also in low socioeconomic classes. ${ }^{12}$ Differences in socioeconomic status, living conditions, average lifespan, and ethnic background may be responsible for the higher occurrence in lower socioeconomic classes, though this is probably related to poor sanitation and hygiene and poor access to healthcare. ${ }^{13}$ The incidence of NCPF has probably declined over the past two decades along with a reduction in the incidence of extrahepatic portal vein obstruction (EHPVO). Umbilical sepsis and/or repeated diarrheal episodes during childhood may play a major role in the pathogenesis of both diseases. Over the years, the improvement in the living standards and the improvement in sanitation and hygiene, also confirmed by the reduced incidence of other diarrheal illnesses, may play a role in the reducing incidence of NCPF and EHPVO. ${ }^{12}$ Perinatal practices have also changed resulting in reducing the frequency of umbilical sepsis in India. ${ }^{12}$

\section{Etiopathogenesis \\ Infectious Theory}

Intra-abdominal infection and infections affecting any of the portal vein drained organs may result in septic embolization to the liver, portal pyemia, or pylephlebitis causing perivenular sclerosis or thrombosis resulting in relative obstruction of small- and medium-sized portal venous radicles. ${ }^{14,15}$ In contrast to others, Japanese investigators believe that thrombosis is secondary to phlebosclerosis. ${ }^{16}$ Animal models have shown portal hypertension and hepatic fibrosis similar to NCPF/IPH after injecting dead coliform bacilli into the portal vein. ${ }^{17}$

\section{Immunological Theory}

Numerous immunological abnormalities are seen in patients with IPH/NCPF. ${ }^{18}$ In 1997, Nundy et $\mathrm{al}^{19}$ found an increased incidence of immune-mediated glomerulonephritis in patients with NCPH who underwent portosystemic shunt surgery as compared to those with normal livers. There is an increased incidence of upregulation of vascular cell adhesion molecule-1 (VCAM-1); ${ }^{20}$ an increased concentration of ET-1 in periportal hepatocytes, portal venules, and hepatic sinusoids of patients with IPH; ${ }^{21}$ and increased connective tissue growth factor (CTGF) promoting fibrosis and phlebosclerosis. ${ }^{22}$ Susceptibility to NCPF may be HLA class II-mediated, with HLA-DR3 influencing susceptibility and DR2 conferring protection. ${ }^{23}$ Data from a Japanese survey showed anti-DNA antibodies in $69.2 \%$ of female patients, antinuclear antibodies in $24 \%$, and antimicrosomal antibodies in $21.5 \% .^{24}$

\section{Xenobiotic Exposure}

Among the suspected xenobiotics, exposure to inorganic arsenic has been the most widely investigated and thought to be the most important. ${ }^{25}$ Histology of liver abnormalities in patients with chronic arsenic exposure and liver dysfunction showed peri-portal fibrosis and multiple vascular channels in the expanded portal zones, as seen in NCPF. ${ }^{26,27}$ Development of arsenic-induced hepatic fibrosis is likely to be related to high hepatic oxidative stress and IL- 6 and TNF-alpha levels. ${ }^{28}$ Chronic exposure to vinyl chloride polymers ${ }^{29}$ or to copper sulfate in vineyard sprayers $^{30}$ has also been thought to be a factor in the development of NCPF. In another report, peri-sinusoidal and portal tract fibrosis were observed in a patient with inhaled mica exposure. ${ }^{31}$

\section{Drugs}

Protracted treatment with methotrexate ${ }^{32}$ and in hypervitaminosis ${ }^{33}$ are is shown to be associated with NCPF. Patients receiving irradiation and chemotherapy ${ }^{34}$ have also been reported to have an increased risk of developing NCPF.

\section{Pathology \\ Gross}

The liver may be normal to markedly nodular. ${ }^{35}$ There is also irregular thickening of the liver capsule (Figure 1). Portal tracts become large due to marked fibrosis (Figure 2). 
On the cut surface, marked fibrosis and hypertrophic nodules may occasionally be seen, compressing the portal vein. ${ }^{7}$ Frequent thrombosis of the large and small portal vein branches has been reported. 7,35 The liver may show extreme distortion with marked nodulation, subcapsular fibrosis, and atrophy of a lobe (Figure 1) and portal vein thrombosis (PVT).

\section{Microscopy}

"Obliterative portal venopathy of liver" is seen as a marked sub-endothelial thickening of the large and medium-sized intrahepatic branches of the portal vein with a patchy segmental distribution (Figure 3). ${ }^{36}$ Organized thrombi with recanalization, scarring of the terminal portal tracts with obliteration or disappearance of the portal vein radicles, and appearance of aberrant vessels are often seen. The lobular architecture and hepatic parenchyma are unaffected. Fibrosis and nodule formation when present affect the subcapsular areas, but not the deeper part of the liver.

\section{Ultrastructure}

Disse's spaces are also widened due to the laying down of collagen, which may extend into the intercellular space. Mesenchymal cells are well developed close to collagen bundles. ${ }^{37}$

\section{Clinical Features}

Patients who have NCPF generally are young and come from low socioeconomic background. The patients commonly present with one or more well-tolerated episodes of gastrointestinal hemorrhage, a long-standing mass in the left upper quadrant (splenomegaly), or consequences of hypersplenism. Development of ascites, jaundice, and hepatic encephalopathy is uncommon. NCPF also may have odd presentations, such as glomerulonephritis ${ }^{38}$ or hypoxemia. ${ }^{39}$ Major presenting symptoms in Japanese patients with IPH seem to be splenomegaly (88\%), hepatomegaly (44\%), gastrointestinal bleeding (35\%), and ascites (12\%). ${ }^{40}$

\section{Investigations}

Patients with NCPF usually show preserved hepatic excretory and synthetic function. ${ }^{41}$ Anemia is not uncommon, and may be secondary to gastrointestinal bleeding or to hypersplenism. Coagulation and platelet function anomalies have also been observed in patients who have $\mathrm{NCPH} .{ }^{42}$ Some have shown a higher incidence of protein $\mathrm{C}$ and $\mathrm{S}$ deficiencies or factor V Leiden mutations. ${ }^{43,44}$ Mild compensated disseminated intravascular coagulation secondary to endotoxemia or portosystemic collaterals has been reported in $67 \%$ of these patients. ${ }^{45}$ Positive antinuclear antibodies and high titers of anti-Scl-70, anti-SS-A, anti-centromere have been reported. Nearly two-thirds of Japanese female patients with IPH were found to test positive for anti-double-stranded DNA and one-fourth tested positive for antinuclear antibody and had hypergammaglobulinemia. ${ }^{46}$

Ultrasonography usually shows a dilated and patent splenoportal axis with significantly thickened walls of the portal vein and its main branches. Doppler ultrasound is useful in identifying thrombosis in the intrahepatic branches of the portal vein. Ultrasound usually shows increased echogenicity of the walls of the portal vessels with a hypoechoic stripe between the wall and the adjacent liver parenchyma. ${ }^{47}$ Subcapsular liver atrophy is frequently observed in such cases. ${ }^{48}$ Aberrant thin-walled collateral vessels adjacent to the portal tracts maintain hepatopetal flow. These aberrant vessels compensate for portal circulatory insufficiency, maintaining an adequate blood supply to the parenchyma. ${ }^{49}$ Portal hypertensive biliopathy is not as commonly seen in patients with $\mathrm{NCPH}$ in contrast with EHPVO. ${ }^{50}$

Endoscopy shows esophagogastric varices in almost $85-95 \%$ of patients with NCPF. Anorectal varices also are also more common (90\% vs 56\%) and are larger. ${ }^{51}$ Gastric varices are more common in NCPF than in cirrhosis and gastropathy developing after variceal obliteration is usually transitory and non-progressive in NCPF. ${ }^{52}$

\section{Differential Diagnosis}

Noncirrhotic portal hypertension generally develops insidiously in contrast to PVT, which may have an acute presentation (sudden increase in variceal size, development of an upper gastrointestinal bleed, abdominal pain, and ascites). Child's A cirrhosis can mimic NCPF, but tests of liver function, viral serology, and findings on liver biopsy (lobular disarray and pseudolobule formation) can distinguish between the two. Moreover, a disproportionately large spleen with a dilated and thickened portal vein favors the diagnosis of NCPF. Tropical splenomegaly syndrome is another condition sometimes seen in the tropics, which presents with massive splenomegaly. However, portal hypertension is uncommon in patients with tropical splenomegaly syndrome and the hepatic wedge pressure is within normal limits.

\section{Management}

Endoscopic sclerotherapy has been shown to be effective in reducing bleeding rates in NCPF in three different studies from India. ${ }^{53-55}$ Endoscopic variceal ligation (EVL) would be a better choice given the fact that it is associated with a lesser number of complications. Both EVL and sclerotherapy are effective in achieving variceal obliteration with a low recurrence rate of about $20 \% .{ }^{56}$ Prevention of rebleeding with the use of nonselective beta-blockers has been reported. ${ }^{56}$ During the acute episode, blood transfusion, intravenous fluids, and standard resuscitative therapy are required. ${ }^{57}$ Gastric varices, which are more common in 


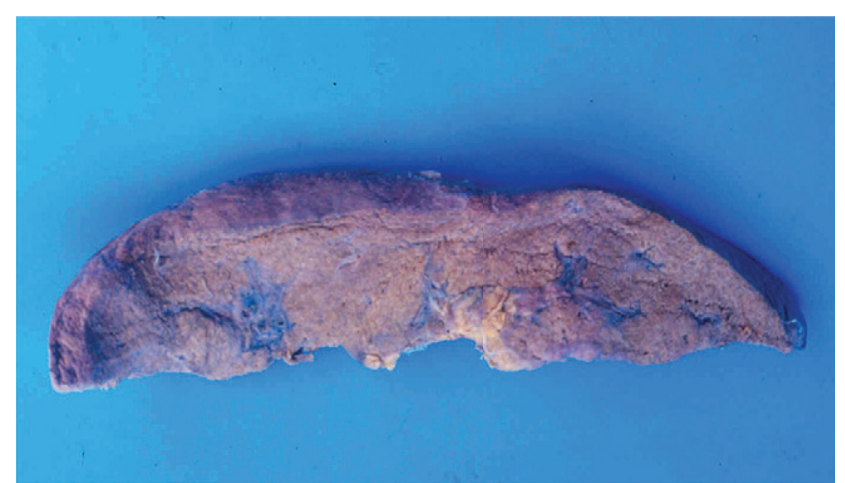

Figure $1 \mathrm{~A}$ coronal slice through liver showing grotesquely enlarged portal tracts due to dense fibrosis, mainly on the inferior aspect of liver.

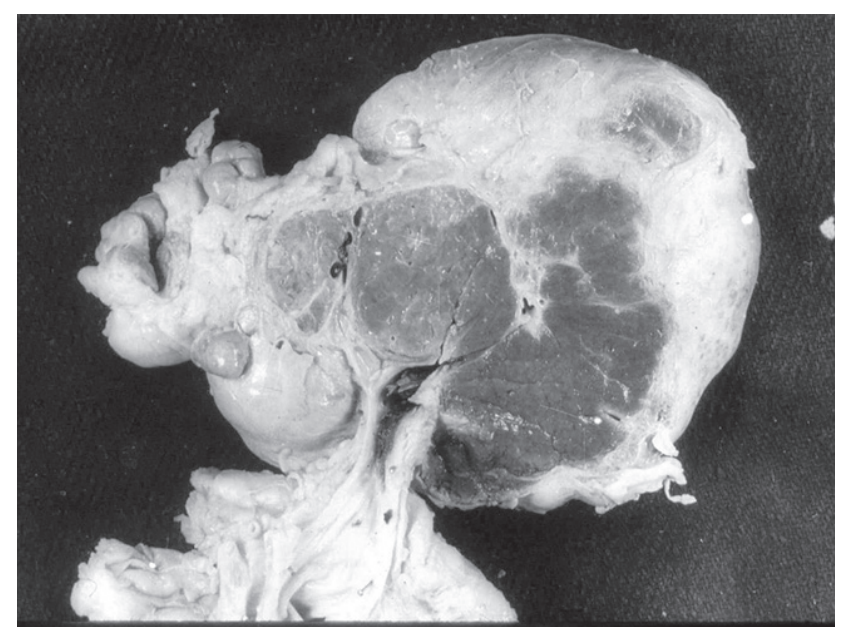

Figure 2 An noncirrhotic portal hypertension liver showing extreme distortion of superio-lateral aspect with marked nodulation, subcapsular fibrosis, atrophic left lobe, and portal vein thrombosis.

NCPF, can be managed with cyanoacrylate glue injection. ${ }^{58,59}$ Splenic artery embolization, percutaneous transhepatic obliteration, and a transjugular intrahepatic portosystemic shunt (TIPSS) are other options in the primary prevention of variceal bleeding. ${ }^{60}$

The role of surgery is limited to those who fail to respond to endoscopic therapy. ${ }^{61}$ Selective shunts, like distal splenorenal shunts, are preferred due to a low incidence of postshunt encephalopathy. If massive splenomegaly is present, splenectomy with a proximal shunt may be done. Surgery is also indicated for symptomatic hypersplenism, for patients with limited access to healthcare, or for those who desire a one-time treatment. Shunt occlusion, overt chronic portosystemic encephalopathy, and rebleeding after elective shunt surgery are seen in about $10 \%$ of patients. ${ }^{62,63}$

Endoscopic therapy is preferred in these young patients where lifelong drug compliance is difficult to maintain. Also, therapy with beta-blockers would be difficult to monitor since the HVPG in these patients is normal. Shunt surgery is effective in NCPF. A decrease in splenic

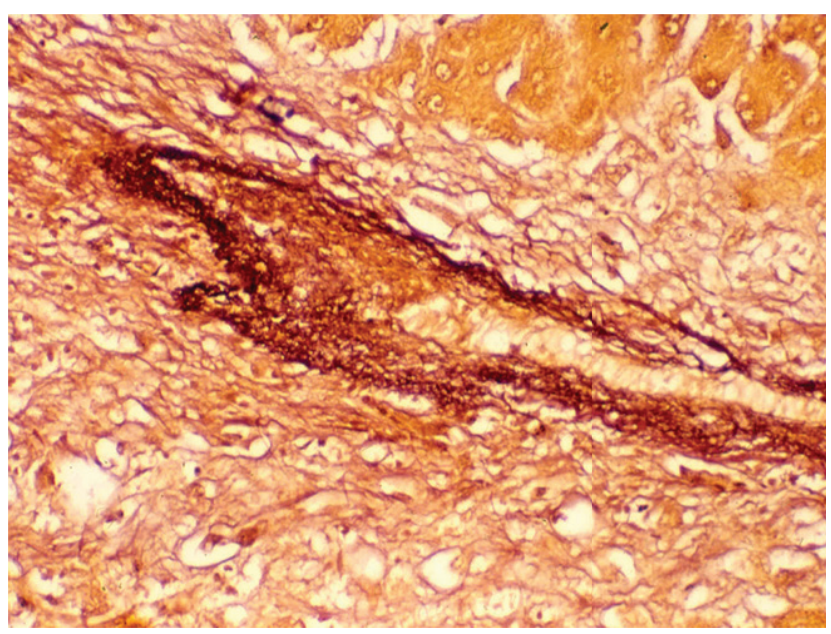

Figure 3 Microphotograph showing a longitudinally cut medium-sized portal vein showing segmental fibroelastotic obliteration (Elastic van Geisen stain, 40x).

pulp pressure and splenic size is seen in patients after successful patent shunt surgery. ${ }^{64}$

\section{Prognosis}

The prognosis of patients with NCPF is generally good. The mortality from an acute variceal bleeding in NCPF is lower than that seen in cirrhotic patients. After successful endoscopic variceal eradication, Sarin and Kumar ${ }^{65}$ observed nearly $100 \% 2$ - and 5-year survival in these patients. The long-term outcome of shunt surgery is also favorable and 5 -year survival of $88 \%$ has been reported. ${ }^{63}$

\section{EXTRAHEPATIC PORTAL VEIN OBSTRUCTION}

Extrahepatic portal vein obstruction is defined as obstruction of the extrahepatic portal vein with or without involvement of the intrahepatic portal veins or splenic or superior mesenteric veins. Isolated occlusion of the splenic vein or superior mesenteric vein does not constitute EHPVO. ${ }^{66}$ Earlier, the term PVT often was exchanged loosely with EHPVO; however, it does not exclude the intrahepatic PVT that is due to cirrhosis of the liver or invasion by hepatocellular carcinoma. The term PVT does not include formation of portal cavernoma and development of portal hypertension that are inherent in chronic portal vein occlusion as in EHPVO. PVT, a known complication of liver cirrhosis and hepatocellular carcinoma, is not included in the disease entity EHPVO.

\section{Epidemiology}

Extrahepatic portal vein obstruction is more often seen in children than in adults, and is again a disease of developing countries and lower socioeconomic strata. In the West, EHPVO accounts for 5-10\% of all cases of portal hypertension, but is higher elsewhere and may reach 
Table 2 Causes of extrahepatic portal vein obstruction.

\begin{tabular}{l}
\hline Idiopathic \\
Portosplenic vein inflammation or injury \\
Umbilical sepsis/portal pyelephlebitis \\
Umbilical catheterization \\
Neonatal peritonitis, abdominal trauma \\
latrogenic operative trauma to the portal vein \\
Indirect causes \\
Neonatal systemic sepsis from non-intraabdominal sources \\
Dehydration \\
Multiple exchange transfusions \\
Hypercoagulable states \\
Myeloproliferative disorders (e.g., polycythemia vera, essential \\
thrombocytosis, and myelofibrosis) \\
Antiphospholipid syndrome \\
Anticardiolipin antibody \\
Protein C, S, antithrombin III deficiency \\
Factor V Leiden deficiency \\
G20210A prothrombin gene mutation \\
Methylene tetrahydrofolate reductase gene mutation (C677T) \\
Hyperhomocysteinemia \\
Paroxysmal nocturnal hemoglobinuria \\
Drugs (e.g., oral contraceptives) \\
Pregnancy \\
Congenital abnormalities \\
Portal vein stenosis \\
Portal vein atresia or agenesis \\
\hline
\end{tabular}

15-20\%. In children, EHPVO accounts for $80-90 \%$ of cases of portal hypertension. ${ }^{66}$ The blockage usually is at the site of portal vein formation (90\%); total blockage of the splenoportal axis is seen in only $10 \%$.

\section{Etiopathogenesis}

Secondary to portal vein blockade, the portal flow is replaced by the formation of multiple dilated tortuous collateral channels around the block constituting a portal cavernoma. The etiology of the portal vein block is not well studied and remains unknown in the majority. The possible causes of EHPVO or conditions leading to EHPVO are shown in Table $2 .^{65}$

\section{Children}

Infection: EHPVO in children may as a result be portal phlebitis with thrombosis as a secondary event. Omphalitis or umbilical sepsis that may be unrecognized has been thought to cause inflammation in the umbilical stump before normal obliteration of these veins. Thrombosis of the portal vein may be secondary to this infection or extension of this infection as portal pyelephlebitis. Umbilical vein cannulation for exchange transfusion could also be responsible for the development of EHPVO. ${ }^{67}$ Other factors such as dehydration may be responsible for increased blood viscosity and a prothrombotic state. ${ }^{68}$

Prothrombotic State: Unlike adults, studies of thrombophilic disorders in children are scanty. In a small number of patients that has been studied, the frequency of prothrombotic disorders was variable. ${ }^{69}$ Despite all efforts, the cause of the blocked portal vein remains obscure in $>50 \%$ of children.

\section{Adults}

In adults, EHPVO is generally synonymous with thrombosis of the extrahepatic portal vein.

\section{Prothrombotic Disorders}

The risk for EHPVO is increased in the presence of thrombophilia resulting from the prothrombin G20210A mutation and from the deficiencies of other anticoagulant factors but not from factor $\mathrm{V}$ Leiden. ${ }^{70}$ The occurrence of thrombophilic disorders in adult patients with EHPVO has been reported. ${ }^{71}$

Surgical trauma or abdominal trauma, a thrombotic stimulus (pregnancy, oral contraceptives, etc.), and the presence of underlying prothrombotic disorder may be causative. In patients where the cause is identified, coagulation disorders account for $60 \%$ of cases, and local factors for $40 \% .{ }^{71}$ PVT follows splenectomy in $6-8 \%$ of cases, ${ }^{72}$ but other interventions including local ablative therapy for $\mathrm{HCC}^{73}$ and fine-needle aspiration of a pancreatic mass ${ }^{74}$ have also been reported to cause PVT.

\section{Pathology}

The portal vein is replaced by a cluster of different sized vessels arranged haphazardly within a connective tissue support, and the original portal vein cannot be identified. Macroscopic appearance of the liver in EHPVO patients varies from smooth to finely granular. ${ }^{66}$ Phlebothrombosis of intrahepatic portal vein branches, although much less common than in NCPF, is a common pathogenic denominator in NCPF and EHPVO. Small intrahepatic portal tracts show cavernomatous transformation in addition to mild portal fibrosis in a majority. Reduction in portal blood flow with concomitant increase in hepatic arterial flow, and more dependence of the liver on hepatic arterial blood in EHPVO may contribute to a relatively reduced functional status of the liver. ${ }^{65}$

\section{Clinical Features}

Extrahepatic portal vein obstruction can present at different ages, from 6 weeks to adulthood, with varied manifestations. The most common presentation is of a child with well-tolerated variceal bleeding and splenomegaly with or without hypersplenism. The clinical features of acute PVT may be seen in adults who develop progressive ascites, abdominal pain, and intestinal ischemia. In patients with neonatal umbilical vein sepsis, EHPVO usually manifests early (average age of onset 3 years) and when it is secondary to intra-abdominal infections or idiopathic, the clinical manifestations are delayed (average age of onset 8 years). ${ }^{75}$ 


\section{JOURNAL OF CLINICAL AND EXPERIMENTAL HEPATOLOGY}

In childhood and early adult life, variceal bleeding, growth retardation, and hypersplenism are the main presenting clinical problems.

\section{Variceal Bleeding}

Usually, EHPVO first presents as a well-tolerated upper variceal bleed. The splenic size and portal pressure do not correlate with the incidence or severity of hematemesis. Rarer problems seen in adults with PVT include venous infarction of the intestines, portal hypertensive biliopathy, massive hemobilia, and pulmonary emboli. ${ }^{66}$

\begin{abstract}
Ascites
Ascites is uncommon and when seen it is of high gradient and develops later during the course of disease. It is usually transient, following hemorrhage or surgery. It is more common in adults than in children. ${ }^{75,76}$ Chronic portal hypertension, marked splanchnic hyperemia, and autonomic dysfunction may contribute to the development of ascites. ${ }^{77}$
\end{abstract}

\section{Ectopic Varices and Hypersplenism}

Ectopic varices (e.g., duodenum, anorectal region, biliary tree, and gallbladder) are also seen in these patients. Patients who have ectopic varices may present with bleeding from the rectum, obscure gastrointestinal bleed, or biliary obstruction. ${ }^{51,78}$ Symptomatic hypersplenism is found in $<5 \%$ of the patients. Occasionally, the massive splenomegaly, or pain due to splenic infarction or perisplenitis, may occur. ${ }^{75}$

\section{Portal Hypertensive Biliopathy}

Portal hypertensive biliopathy refers to biliary changes like indentations of para-choledochal collaterals on the bile duct, localized strictures, angulation of ducts, dilatations, irregular walls, and clustering of intrahepatic branches in the hepatic ducts. ${ }^{50,65}$ Although biliopathy is seen in $>80 \%$ patients, only a few are symptomatic. ${ }^{50}$ Symptomatic patients usually are adults, which indicate that portal hypertensive biliopathy might be a progressive disease. Symptomatic portal hypertensive biliopathy may be due to chronic cholestasis, and may cause cholangitis, stones, or biliary pain. Diagnosis is best made with endoscopic retrograde cholangio pancreatography (ERCP) or magnetic resonance cholangio pancreatography (MRCP) examination. ${ }^{50}$

\section{Growth Retardation}

Nearly one-third patients with EHPVO are of short stature and have significantly diminished growth velocity. This could be a result of deprivation of the portal blood that has hepatotrophic factors in it or as a result of portal gastroenteropathy. ${ }^{79}$ Growth spurts have been observed after shunt surgery in patients who have EHPVO. ${ }^{80}$

\section{Autonomic Dysfunction}

Impaired cardiovascular autonomic reflexes occur in subjects who have portal hypertension that is due to EHPVO. Hypoxemia has also been documented in case reports in patients with EHPVO because of intrapulmonary vascular dilatations. $^{77}$

Presence of upper gastrointestinal bleeding and the absence of jaundice are $97.5 \%$ accurate in predicting diagnosis of EHPVO in children. Low hemoglobin and preserved liver functions characterized by normal bilirubin, albumin levels, and prothrombin time were observed in patients with EHPVO. Cirrhotic patients have higher hemoglobin and abnormal liver function tests.

\section{Investigations and Diagnosis}

Upper gastrointestinal bleeding or just the presence of esophageal varices in a child/young adolescent with normal or near normal liver function tests should raise the suspicion of EHPVO. Imaging remains the cornerstone for the diagnosis of EHPVO. Tests of liver function are generally within the normal range. ${ }^{65}$ A peripheral blood count may reveal variable evidence of hypersplenism with anemia or low platelet and white cell counts. Ultrasound is economic and precise (94-100\% sensitive and $96 \%$ specific ${ }^{66}$ for the detection of portal cavernoma and is the investigation of choice. Contrast-enhanced CT, CT arterial portography, and MR angiography/venography also have a high degree of sensitivity and specificity.

\section{Management}

The management of EHPVO predominantly includes the treatment of variceal bleeding, hypersplenism, and portal hypertensive biliopathy.

Endoscopic variceal ligation or endoscopic sclerotherapy is equally efficacious for management of varices. ${ }^{81}$ Patients with portal hypertension and varices who have not bleed do not need treatment and can be observed, as they may never bleed for many years. Hypersplenism is by itself not an indication for surgical intervention, but profound thrombocytopenia with bleeding, repeated infections, or physical discomfort caused by massive splenomegaly may merit splenectomy. Shunt surgery is reserved for patients who fail endoscopic therapy or patients with symptomatic portal hypertensive biliopathy, symptomatic hypersplenism, or growth retardation. Patients who have poor access to healthcare may also benefit from shunt surgery as a one-time treatment. ${ }^{65}$ Total and selective shunts can be used, but selective shunts like distal splenorenal shunt (DSRS) are preferred. ${ }^{82}$ Rex shunt (mesenterico-left portal vein bypass) in children who have EHPVO is considered to be the treatment of choice because they restore normal portal flow to the liver. ${ }^{83}$

Symptomatic portal hypertensive biliopathy is a definite indication for intervention and depends upon its presentation. Definitive treatment may be in the form of 
shunt surgery/TIPSS. ${ }^{50}$ Endoscopic treatment is effective in the management of cholangitis and choledocholithiasis, and in temporarily relieving biliary obstruction. Surgical portosystemic shunting or TIPSS is indicated to relieve the portal hypertension which is not relieved by endoscopy. In patients with persistent obstruction, hepaticojejunostomy may be needed. An algorithm for the management of a patient with portal hypertensive biliopathy has been recently suggested (Figure 4).
Acute PVT is usually symptomatic and required anticoagulation for 3-6 months. If an underlying hypercoagulable state is identified, lifelong anticoagulation may be considered. ${ }^{86}$

\section{SCHISTOSOMIASIS}

Human schistosomiasis is caused by five species of the parasitic trematode genus Schistosoma: the intestinal species

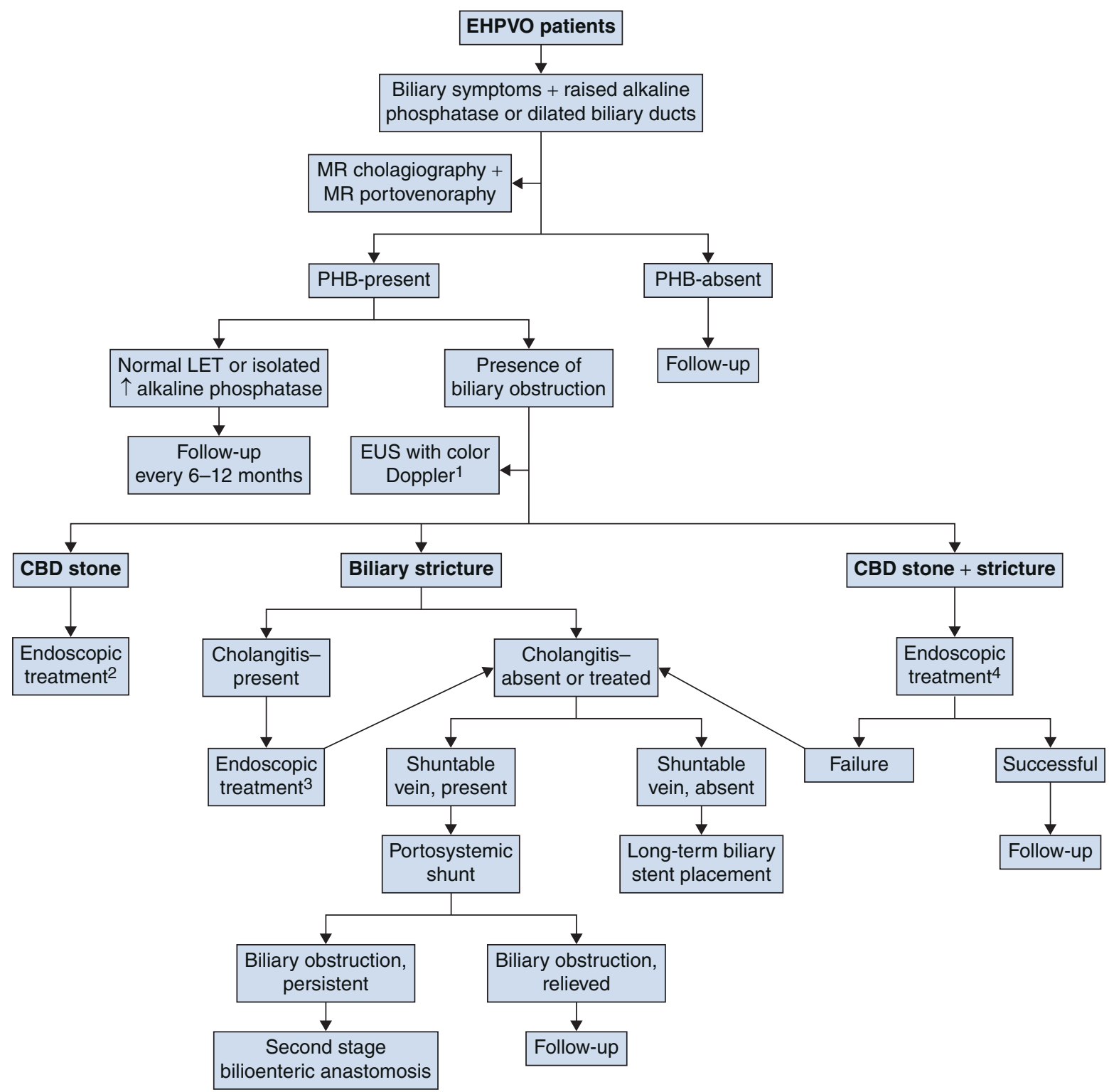

Figure 4 Algorithm for the management of a patient with portal hypertensive biliopathy. EHPVO: extrahepatic portal venous obstruction; CBD: common bile duct; LFT: liver function tests; MR: magnetic resonance; PHB: portal hypertensive biliopathy; EUS with color Doppler ${ }^{1}$ for evaluation of biliary obstruction when other imaging modalities are unrevealed, EUS is also helpful in identifying intracholedochal or intramural collaterals which are useful in stratifying the patient as low or high risk for CBD stone removal or CBD stricture dilatation; ${ }^{4}$ endoscopic treatment ${ }^{2}$ includes endoscopic sphincterotomy, stone extraction with or without the help of mechanical lithotripsy; endoscopic treatment ${ }^{3}$ includes nasobiliary drain or biliary stent placement; endoscopic treatment ${ }^{4}$ includes endoscopic sphincterotomy and stricture dilatation, followed by stone extraction with or without the help of mechanical lithotripsy. ${ }^{85}$ 


\section{JOURNAL OF CLINICAL AND EXPERIMENTAL HEPATOLOGY}

S. mansoni, S. japonicum, S. mekongi, and S. intercalatum and the urinary species $S$. haematobium. Presinusoidal portal blockage causes portal hypertension and associated development of portosystemic collaterals, splenomegaly, and various other changes associated with portal hypertension. ${ }^{87}$ The second most significant pathologic change is characteristically periportal fibrosis (Symmers' clay pipestem fibrosis) and is also seen in distant portal tracts.

\section{Pathogenesis}

The presence of a high worm load is not required for the development of schistosomal hepatopathy. The large majority of those infected present mild forms of the infection, while only a few develop severe manifestations. Infected people who emigrate from an endemic area rarely develop pipe-stem fibrosis. ${ }^{88}$ The influence of re-infection in pathogenesis cannot be ruled out. Ova that are carried by portal blood lodge at presinusoidal sites where granulomas are formed and fibrosis occurs. Interleukin (IL)-2, IL-4, IL-1, and transforming growth factor- $\beta$ are known to stimulate fibrogenesis, and regulatory cytokines interferon- $\gamma$ or IL-12 may play a role in modulating the response. ${ }^{89}$ HLA types A1 and B5 and a gene closely linked to interferon- $\gamma$ receptor gene on chromosome 6 are probably closely linked to development of disease. ${ }^{90}$ Collaterals are formed, which are progressively involved by ova, resulting in inflammation, fibrosis, and vascular obliteration along all the periportal spaces. ${ }^{88}$

Periportal fibrosis was classified by Coelho: ${ }^{91}$

- Degree I-portal and periportal inflammation and fibrosis.

- Degree II-expansion of portal connective tissue and fibrosis with septal fibrosis.

- Degree III-bridging fibrosis with evident neoangiomatoid formation.

\section{Clinical Features}

The clinical manifestation of hepatic schistosomiasis resembles presinusoidal portal hypertension akin to NCPF/IPH or EHPVO, with a history of one or multiple episodes of variceal bleeding, prominent splenomegaly, no ascites, and normal liver functions. ${ }^{92}$ Splenomegaly in hepatic schistosomiasis is massive and is caused by infiltration with inflammatory cells and passive congestion. Patients are often young, with no sexual preponderance, and usually look well, most frequently seeking medical attention for discomfort from splenomegaly or after an episode of upper gastrointestinal bleeding. ${ }^{92}$ Splenomegaly is congestive, but also results from reticuloendothelial hyperplasia. Enlargement of the spleen is a well-recognized feature of acute schistosomiasis (Katayama fever). ${ }^{93}$

The spleen may be visibly enlarged and may result in "hypersplenism," but this is rarely of clinical significance.
Anemia is unusual but may result from occult gastrointestinal blood loss. Hepatosplenomegaly is usual and the portal hypertension presinusoidal in type. ${ }^{94}$ Patients can present with well-tolerated upper gastrointestinal bleeding. Some patients present with ascites with signs of chronic liver disease. In such patients, liver function may be deranged, though why some cases decompensate is not known. ${ }^{95}$ Cheever and Andrade ${ }^{96}$ reported active portal triaditis with limiting plate and piecemeal necrosis in patients with decompensated hepatosplenic schistosomiasis. This pattern, which is typical of chronic hepatitis, was not seen in compensated hepatosplenic schistosomiasis. ${ }^{96}$

\section{Diagnosis}

Tropical splenomegaly syndrome (hyper-reactive malarial splenomegaly), schistosomiasis, visceral leishmaniasis, and, more rarely, trypanosomiasis are important causes of splenomegaly in the tropics. ${ }^{97}$ The gold standard for the diagnosis of hepatic schistosomiasis is the finding of schistosomal eggs and calcified or noncalcified schistosomal granuloma in liver biopsy specimens. However, this has poor sensitivity due to sampling error and the nonuniform nature of liver involvement; so the practical diagnosis is by finding periportal fibrosis on ultrasonography combined with high-titer anti-schistosomal antibodies in serum.

Infection may be diagnosed microbiologically or immunologically. Fecal examination is best carried out using a concentration method such as the Kato technique, ${ }^{98}$ although in heavy infections ova may be readily detected in a single wet smear. Sero-diagnostic techniques in schistosomiasis have been reviewed by Smithers and Doenhoff. ${ }^{99}$ Enzyme-linked immunosorbent assay has been the most successful immunodiagnostic technique for S. mansoni infection. Serology is incapable of distinguishing between simple infections and hepatosplenic disease. Liver biopsy, though useful, may be misleading. ${ }^{100}$ Granulomata and hemozoin pigment may be frequent findings in apparently healthy individuals, and the stool may contain ova in apparently healthy individuals.

\section{Management}

Treatment of schistosomiasis includes treatment of the parasitic infection and management of portal hypertension.

The most frequent drugs are praziquantel, oxamniquine, hycanthone, and niridazole. ${ }^{101}$ Praziquantel is the drug of choice. Two oral doses of $25-30 \mathrm{mg} / \mathrm{Kg}$ at an interval of $4 \mathrm{~h}$ are usually adequate treatment for $S$. mansoni infection. Repeated chemotherapy with praziquantel might accelerate protective immune responses by increasing exposure to antigens that induces a T-helper type- 2 response. ${ }^{102}$ Metrifonate is relatively inexpensive and can be used in conjunction with oxamniquine for treatment of mixed infections with $S$. haematobium and S. mansoni. 
Oxamniquine is also well tolerated and is effective only against $S$. mansoni. Niridazole should no longer be used in view of its high frequency of side effects.

\section{Treatment of Portal Hypertension and Variceal Bleeding}

After resuscitation, emergency endoscopy should be done to determine that bleeding is variceal in origin. Endoscopic band ligation has shown encouraging results. ${ }^{103}$ Betablockers could be used in a similar fashion as in other liver diseases. $^{104}$

Surgical treatment is indicated in the definitive or in the long-term treatment of the portal hypertension resulting from schistosomiasis. Surgery is superior to endoscopic and medical therapy for secondary prophylaxis of variceal bleed. The classical proximal splenorenal shunt imposes a high risk of encephalopathy, which is not seen after distal splenorenal selective shunt-Warren shunt. ${ }^{105}$ Surgical options of portosystemic shunting and devascularization with splenectomy have been reported.

The management of variceal bleeders by distal splenorenal shunt or by esophagogastric devascularization achieves low operative mortality, though a higher rate of variceal rebleeding after esophagogastric devascularization (>25\%) and a higher rate of encephalopathy after distal splenorenal shunt $(>15 \%) .{ }^{106}$ Both surgical procedures have similar cumulative survival, with rates of $80 \%$ and $79 \%$, respectively.

\section{CONGENITAL HEPATIC FIBROSIS}

Congenital hepatic fibrosis (CHF) is an autosomalrecessive inherited malformation defined pathologically by a variable degree of periportal fibrosis and irregularly shaped proliferating bile ducts. CHF is one of the fibropolycystic diseases, which also include Caroli disease, autosomal-dominant polycystic kidney disease, and autosomal-recessive polycystic kidney disease. ${ }^{107}$ Clinically, it is characterized by hepatic fibrosis, portal hypertension, and renal cystic disease. Patients usually present with symptoms of recurrent cholangitis and symptoms related to portal hypertension.

\section{Clinical Features}

Onset of symptoms and signs is variable and ranges from early childhood to the sixth decade of life, though most patients present during young adulthood. ${ }^{107}$ In most patients, the first manifestations of the disease are signs or symptoms related to portal hypertension-often with spontaneous gastrointestinal bleeding which is usually well tolerated. Four clinical forms have been defined: ${ }^{107}$

1. Portal hypertension

2. Cholangitic-cholestasis and recurrent cholangitis

3. Mixed

4. Latent-presentation at a late age

\section{Pathology and Pathogenesis}

Congenital hepatic fibrosis and Caroli's disease closely resemble each other pathophysiologically, since both occur as a result of ductal plate malformation. Depending on the stage of arrest of maturation, either the small interlobular bile ducts (CHF) or the medium intrahepatic bile ducts (Caroli's disease) or both (Caroli's syndrome) may be involved. ${ }^{107}$ Portal hypertension has been attributed to the compression of portal vein radicles in the fibrous bands and to anomalous branching pattern of the portal vein.

\section{Diagnosis}

Ultrasound, CT scanning, and MRI are all useful in the demonstration of portal hypertension and subsequent portal cavernoma. ${ }^{108,109}$ MRI can also evaluate the bile ducts with MRCP to assess the presence of cystic lesions of the biliary tree. An unequivocal diagnosis of CHF involves a liver biopsy. The classical histological findings ${ }^{110}$ are degrees of hepatic fibrosis with nodular formation, which may become extensive as the disease progresses. Unlike cirrhosis, hepatic lobules are usually normal with normal hepatocyte morphology. Cystic dilatation of bile ducts (Caroli's disease) and hypoplasia of the portal vein branches in association with supernumerary hepatic artery branches may be seen.

\section{Treatment}

Antifibrotic agents are used with limited success in patients having diverse conditions, including cirrhosis with the presence of histological improvement in a few. The treatment of CHF remains in the management of portal hypertension and splenomegaly with or without hypersplenism. ${ }^{107}$

Endoscopic treatment is indicated for the prophylaxis of variceal bleeding, as well as in the setting of acute bleeding. Similarly, the management of recurrent attacks of cholangitis associated with Caroli's syndrome involves antibiotics, drainage, and stone extraction using ERCP. ${ }^{107}$

\section{Surgery}

Surgical shunts/TIPSS may be indicated for variceal bleeding not satisfactorily managed with endoscopic therapy. Options include total and partial portosystemic shunts, partial shunts maintaining some ante-grade blood flow to the liver, and selective portosystemic shunts which achieve variceal decompression through the splenic vein to the left renal vein. Caroli's disease with recurrent bouts of cholangitis may need partial liver resection in case of heterogeneous involvement of the liver. Liver transplantation is the only curative treatment for CHF. ${ }^{107}$ Long-term follow-up of surgical shunts has shown that $39 \%$ of patients have jaundice, $17 \%$ have recurrent bleeding, and $17 \%$ have hepatic encephalopathy. ${ }^{111}$ 


\section{NODULAR REGENERATIVE HYPERPLASIA OF THE LIVER}

Nodular regenerative hyperplasia (NRH) is defined by the occurrence of nodules of regenerative hepatocytes, diffusely distributed all over the hepatic parenchyma; in the absence of fibrosis. ${ }^{112}$ The prognosis depends on the existence and severity of portal hypertension, which occurs in about $50 \%$ of cases.

\section{Etiology}

The critical lesion is obliterative portal venopathy, causing obstruction to terminal radicals of hepatic arterioles, and portal venules. ${ }^{113}$ It is believed that nodular regenerative hyperplasia is a secondary and nonspecific tissue adaptation to heterogeneous distribution of blood flow and does not represent a specific entity. The exact pathogenesis of $\mathrm{NRH}$ is incompletely understood. It may occur in response to heterogeneous perfusion of liver tissue with atrophy of poorly perfused areas and hyperplasia of normally perfused areas. ${ }^{112,114,115}$ A possible pathogenicity as a premalignant condition which may progress to hepatocyte dysplasia and hepatocellular carcinoma has also been attributed to NRH. ${ }^{116}$

Some cases of NRH have been attributed to toxic liver injury, after treatment with azathioprine or as part of the toxic oil syndrome. NRH is currently thought to be secondary to microcirculatory disturbances within the liver parenchyma, inducing successive episodes of atrophy followed by compensatory regeneration. ${ }^{116}$

\section{Pathology}

The liver surface may be smooth or finely nodular. The nodules are uniform in size and rarely $>0.5 \mathrm{~cm}$ in diameter. ${ }^{117}$ The characteristic histologic feature is the presence of nodules of approximately lobular size. The hepatocytes at the periphery of the nodules appear to be atrophic and have small, uniform nuclei, whereas those in the center are enlarged and occasionally binucleate. ${ }^{117}$

\section{Clinical Features and Management}

A small proportion of patients may go on to develop hepatic decompensation after long-term follow-up. ${ }^{118}$ The usual presentation is with variceal bleeding and splenomegaly with relatively normal liver synthetic function. ${ }^{119}$ Variceal bleeding is treated like any other case of portal hypertension. Endoscopic therapy is useful for acute management as well as secondary prophylaxis of variceal bleeding. Portosystemic shunting, either surgical or transjugular intrahepatic portosystemic shunt placement (TIPS), has also been used with varying success in the management of portal hypertension. ${ }^{120}$ Splenomegaly is usually mild and hypersplenism is unusual. In late cases, liver transplantation may be required with decompensation of liver function.

\section{BUDD-CHIARI SYNDROME}

Budd-Chiari syndrome (BCS) is a relatively rare disorder caused by obstruction of hepatic venous outflow anywhere from the small hepatic veins to the supra-hepatic inferior vena cava (IVC). ${ }^{121}$ Hepatic outflow obstruction related to right-sided cardiac failure or to sinusoidal obstruction syndrome (also known as veno-occlusive disease $[\mathrm{VOD}])^{122}$ is not included in the definition of BCS.

\section{Etiology}

Budd-Chiari syndrome (BCS) can be further classified as primary or secondary, depending on the underlying cause and the nature/type of venous obstruction. If an endoluminal venous lesion is present, such as thrombosis or an IVC web, BCS is considered primary. The secondary form consists of venous obstruction caused by external invasion or compression of the venous lumen, as is the case with malignant tumors or large cysts.

Most patients with BCS have an underlying risk factor predisposing to a thrombotic state. Both inherited and acquired procoagulant disorders have been associated with BCS (Table 3), of which myeloproliferative disorders are the most common. ${ }^{123}$ Approximately $50 \%$ of patients with $\mathrm{BCS}$ are shown to have an underlying myeloproliferative disorder. $^{123}$

\section{Clinical Features}

The classical clinical triad consists of abdominal pain, ascites, and hepatomegaly. Other possible symptoms are nausea, fever, and jaundice. ${ }^{124-126}$ The severity of symptoms depends on the extent of thrombosis, the rapidity of onset, and the compensatory collateral circulation.

Budd-Chiari syndrome (BCS) should be suspected in patients with abdominal pain and an enlarged liver, in fulminant hepatic failure (FHF) with ascites, and chronic refractory ascites if liver function tests are near normal. ${ }^{124-126}$ There is a high serum ascites albumin gradient. Despite the major hemodynamic changes involving the liver, synthetic function is often relatively spared.

Table 3 Etiological factors in Budd-Chiari syndrome.

Prothrombotic conditions
Factor V Leiden mutation
Antiphospholipid syndrome, antithrombin III deficiency
Protein C, S deficiency, hyperhomocysteinemia
Myeloproliferative disorders
Polycythemia vera
Essential thrombocytosis
Paroxysmal nocturnal hemoglobinuria
Oral contraceptive use
Pregnancy
Cancer
Anatomic webs (inferior vena cava and hepatic veins)
Behcet's syndrome
Polycystic liver disease


During the course of the disease, portal hypertension frequently develops and may be complicated by variceal bleeding. Less common, an episode of gastrointestinal bleeding is the first presenting sign of BCS. ${ }^{127}$ Ascites is an important complication of hepatic venous obstruction and a frequent cause of morbidity.

The traditional classification of BCS by severity of presentation has led to the description of fulminant (5\%), acute (20\%), and subacute or chronic BCS (60\%), in reported series. The prognostic value of this classification scheme has not been prospectively validated, however, and several authors no longer recommend using it to predict mortality. ${ }^{128}$

Budd-Chiari syndrome (BCS) is classified into four disease types according to the site of the venous obstruction and the presence or absence of PVT: hepatic vein obstruction without IVC obstruction, hepatic vein obstruction with IVC obstruction, isolated hepatic webs, and isolated IVC webs. ${ }^{129}$

\section{Management}

Anticoagulant therapy is initiated to prevent extension of the thrombosis. Lifelong anticoagulation is recommended in all patients with thrombotic BCS, providing that there are no contraindications. ${ }^{130}$ Patients with fulminant BCS and liver failure ideally require liver transplantation as there is usually too much necrosis. ${ }^{131}$ In patients with acute BCS, early thrombolytic therapy used within $72 \mathrm{~h}$ of diagnosis has had variable success. ${ }^{132}$

Short-segment obstruction or webs in hepatic veins or the IVC are treated successfully by balloon dilatation or intravascular stents. Membranous venacaval obstruction can be relieved initially by these means in $90 \%$ of patients, but $20-30 \%$ will need additional angioplasty. ${ }^{133}$

Transjugular intrahepatic portosystemic shunt placement is accepted as initial therapy in patients with BCS refractory to medical therapy and in fulminant BCS. TIPS may be a bridge to liver transplantation. The goal of treatment of BCS is reduction of hepatic congestion and associated sequelae such as significant ascites. TIPS achieves this objective and results in symptomatic relief in a majority of patients. ${ }^{134}$ Surgical portosystemic shunting is another option in the management of esophageal varices due to portal hypertension. Liver transplantation is indicated in patients that have progressed to liver cirrhosis. Emergency liver transplantation is indicated for fulminant BCS.

\section{HEPATIC VENO-OCCLUSIVE DISEASE (SINUSOIDAL OBSTRUCTION SYNDROME)}

Hepatic VOD is a clinical syndrome characterized by hepatomegaly, ascites, weight gain, and jaundice. ${ }^{135}$ It was first described in a patient who drank an infusion made with pyrrolizidine alkaloids. ${ }^{136}$

Veno-occlusive disease (VOD) is also associated with other toxins and drugs such as alcohol, oral contraceptives, toxic oil, terbinafine, radiation injury, and chemotherapy after stem-cell transplantation (SCT). ${ }^{137}$ VOD after SCT is a part of the spectrum of multiorgan syndromes which include idiopathic pneumonitis, diffuse alveolar hemorrhage, thrombotic microangiopathy, and capillary leak syndrome. ${ }^{137}$

Currently, the incidence and severity of VOD after SCT is decreasing as a result of various advances in SCT. VOD is also reported after other solid organ transplantation, particularly kidney transplantation, mainly related to azathioprine toxicity. In liver transplant recipients, the largest series reported an incidence of 1.9\% (19/1023 liver transplants) clinical VOD, related to the number and severity of rejection episodes and azathioprine use. Reversible hepatic venule stenosis related to azathioprine has been reported in $43 \%$ after liver transplantation. ${ }^{138}$

\section{Pathogenesis and Histology}

High-dose cytotoxic chemotherapy used in susceptible patients produces endothelial injury in both sinusoids and small hepatic venules. Subsequent necrosis and inflammation results in occlusion of the sinusoids, causing intrahepatic postsinusoidal portal hypertension. ${ }^{139}$ Release of cytokines, such as tumor necrosis factor-alfa (TNF- $\alpha$ ), interleukin-1 (IL1), and 2, has a procoagulant activity. Genetic and secondary susceptibility of the liver may also play a major role. Patients with previous liver disease, previous liver radiation, or hepatitis are more prone to develop VOD. ${ }^{140}$

\section{Clinical Features}

The classic presentation of VOD is characterized by the triad of weight gain caused by fluid retention, tender hepatomegaly, and hyperbilirubinemia without any known cause. ${ }^{137}$ Usually, this occurs within 3 weeks after SCT when regimens containing cyclophosphamide have been used. With other regimens, it may occur later. ${ }^{141}$ After liver transplantation, VOD occurs over wide intervals, with a mean of 9 weeks after the transplant surgery. ${ }^{142}$ Viral infections, graft versus host disease, sepsis, heart failure, and tumoral infiltration of the liver need to be excluded. The elevation of serum CA-125 appears to be an early and accurate predictive marker of VOD in the pediatric population, but the mechanism is unknown. ${ }^{143}$ Criteria have been laid down to aid in the diagnosis of VOD after SCT (Table 4).

\section{Investigations}

Ultrasound of the abdomen reveals ascites with hepatomegaly and attenuated hepatic veins and/or biliary dilatation. ${ }^{144}$ Doppler ultrasound can suggest VOD on the basis of a decreased or a reversed portal venous flow. ${ }^{145}$ Interestingly, the thickness of gallbladder wall has been shown to correlate with HVPG in these patients. ${ }^{146}$

Moreover, HVPG can help discriminate between graftversus-host disease and VOD, especially after SCT or 
Table 4 Diagnostic criteria of veno-occlusive disease after stem-cell transplantation. ${ }^{144}$

\begin{tabular}{l}
\hline Seattle criteria \\
At least two of the following three criteria within the first month \\
after stem-cell transplantation (SCT): \\
1. Jaundice \\
2. Hepatomegaly and right upper quadrant pain \\
3. Ascites and/or unexplained weight gain \\
Baltimore criteria \\
Elevated total serum bilirubin ( $\geq 2 \mathrm{mg} / \mathrm{dL}$ ) before day 21 after SCT \\
and two of the following three criteria: \\
1. Tender hepatomegaly \\
2. Weight gain $\geq 5 \%$ from baseline \\
3. Ascites \\
Modified Seattle criteria \\
Occurrence of two of the following events within 20 days of SCT: \\
1. Hyperbilirubinaemia ( $\geq 2 \mathrm{mg} / \mathrm{dL})$ \\
2. Hepatomegaly or right upper quadrant pain of liver origin \\
3. Unexplained weight gain $(>2 \%$ of baseline bodyweight) \\
because of fluid accumulation
\end{tabular}

organ transplantation, because HVPG is high in VOD. ${ }^{146}$ A HVPG $>20 \mathrm{mmHg}$ is correlated with poor prognosis. ${ }^{147}$ Transjugular liver biopsy can be done at the time of HVPG measurement and diagnosis confirmed.

\section{Management}

Treatment of VOD is primarily supportive and spontaneous recovery is reported in $70-85 \%$ of mild forms after SCT. The use of non-myeloablative regimens in patients with risk factors for VOD is now possible. The study of genetic polymorphisms of glutathione S-transferase and TNF- $\alpha$ has been evaluated and allows identification of the patients at risk, but further studies are needed. ${ }^{148}$ Treatment of the classical VOD is mainly supportive, including treatment of ascites with sodium restriction, diuretics, and paracentesis.

Based on the histological presence of microthrombosis and fibrin deposition in the hepatic venules of patients with VOD, the principal specific therapy has been to promote fibrinolysis with or without anticoagulation. ${ }^{147}$ Agents like tissue plasminogen activator with heparin, antithrombin 3, protein $\mathrm{C}$, prostaglandin $\mathrm{E} 1$, and defibrotide have been used in the treatment of VOD after sickle cell disease and organ transplantation with limited success. ${ }^{146}$

\section{CONFLICTS OF INTEREST}

All authors have none to declare.

\section{REFERENCES}

1. Sanyal AJ, Bosch J, Blei A, Arroyo V. Portal hypertension and its complications. Gastroenterology 2008;134:1715-28.

2. Banti G. Splenomegalie mit Leberizirrhose. Beitrage zur pathologischen [Splenomegaly with liver cirrhosis. Contribution to pathology]. Anat Allgemeinea Pathol 1889;24:21-33.
3. Ravenna P. Banti syndrome (fibrocongestive splenomegaly). Definition, classification and pathogenesis. Arch Intern Med 1940; 66:879-92.

4. Mikkelsen WP, Edmondson HA, Peters RL, Redeker AG, Reynolds TB. Extra- and intrahepatic portal hypertension without cirrhosis (hepatoportal sclerosis). Ann Surg 1965;162:602-20.

5. Levison DA, Kingham JG, Dawson AM, Stansfeld AG. Slow cirrhosis or no cirrhosis? A lesion causing benign intrahepatic portal hypertension. J Pathol 1982;137:253-72.

6. Polish E, Christie J, Cohen A, Sullivan B Jr. Idiopathic presinusoidal portal hypertension (Banti's syndrome). Ann Intern Med 1962; 56:624-7.

7. Boyer JL, Sen Gupta KP, Biswas SK, et al. Idiopathic portal hypertension. Comparison with the portal hypertension of cirrhosis and extrahepatic portal vein obstruction. Ann Intern Med 1967;66:41-68.

8. Basu AK, Boyer J, Bhattacharya R, et al. Non-cirrhotic portal fibrosis with portal hypertension: a new syndrome. I. Clinical and function studies and result of operations. II. Histopathological studies. Ind J Med Res 1967;55:336-9.

9. Kobayashi Y, Inokuchi K, Saku M. Epidemiology of idiopathic portal hypertension based on a nation-wide survey. Report of the Ministry of Health and Welfare Research Committee on Idiopathic Portal Hypertension. Tokyo: Japan Ministry of Health and Welfare; 1976:10-5.

10. Okuda K, Nakashima T, Okudaira M, et al. Liver pathology of idiopathic portal hypertension. Comparison with NCPF of India. Liver 1982;2:176-92.

11. Halllenbeck GA, Adson MA. Esophagogastric varices without hepatic cirrhosis. A clinical study of treatment of their bleeding in 72 cases. Arch Surg 1961;83:370-83.

12. Sarin SK, Kumar A, Chawla YK, et al. Non-cirrhotic portal fibrosis/ idiopathic portal hypertension: APASL recommendations for diagnosis and treatment. Hepatol Int 2007;1:398-413.

13. Sama SK, Bhargawa S, Gopi Nath N, et al. Non-cirrhotic portal fibrosis. Am J Med 1971;51:160-9.

14. Sarin SK. Non-cirrhotic portal fibrosis. Gut 1989;5:336-51.

15. Okudaira M, Ohbu M, Okuda K. Idiopathic portal hypertension and its pathology. Semin Liver Dis 2002;22:59-72.

16. Okuda K. Non-cirrhotic portal hypertension versus idiopathic portal hypertension. J Gastroenterol Hepatol 2002;17(Suppl 3):S204-13.

17. Kohno K, Ohnishi K, Omata M, et al. Experimental portal fibrosis produced by intraportal injection of killed nonpathogenic Escherichia coli in rabbits. Gastroenterology 1988;94:787-96.

18. Sarin SK, Nayyar AK, Malhotra P, Sharma BK, Kumar R, Broor SL. Immunological profile of patients with non-cirrhotic portal fibrosis. J Gastroenterol Hepatol 1990;5:425-31.

19. Dash SC, Bhuyan UN, Dinda AK, et al. Increased incidence of glomerulonephritis following spleno-renal shunt surgery in noncirrhotic portal fibrosis. Kidney Int 1997;52:482-5.

20. Yamaguchi N, Tokushige K, Haruta I, Yamauchi K, Hayashi N. Analysis of adhesion molecules in patients with idiopathic portal hypertension. J Gastroenterol Hepatol 1999;14:364-9.

21. Yamaguchi E, Yamanoi A, Ono T, Nagasue N. Experimental investigation of the role of endothelin-1 in idiopathic portal hypertension. J Gastroenterol Hepatol 2007;22:1134-40.

22. Morikawa H, Tamori A, Nishiguchi S, et al. Expression of connective tissue growth factor in the human liver with idiopathic portal hypertension. Mol Med 2007;13:240-5.

23. Taneja V, Mehra NK, Sarin SK, Sharma BK, Vaidya MC. Possible HLA influence in governing susceptibility to non-cirrhotic portal fibrosis. Tissue Antigens 1987;30:184-7.

24. Nakanuma Y, Nonomura A, Hayashi M, et al. Pathology of the liver in "idiopathic portal hypertension" associated with autoimmune disease. The Ministry of Health and Welfare Disorders of Portal Circulation Research Committee. Acta Pathol Jpn 1989;39: 586-92. 
25. Abernathy C, Liu YP, Longfellow D, et al. Arsenic: health effects, mechanisms of actions and research issues. Environ Health Perspective 1999;107:593-7.

26. Santra A, Das Gupta JD, De B, Roy B, Guha Mazumder DN. Hepatic manifestations in chronic arsenic toxicity. Ind $J$ Gastroenterol 1999;18:152-5.

27. Huet PM, Guillaume E, Cote J, Legare A, Lavoie P, Viallet A. Noncirrhotic presinusoidal portal hypertension associated with chronic arsenical intoxication. Gastroenterology 1975;68:1270-7.

28. Das S, Santra A, Lahiri S, Guha Mazumder DN. Implications of oxidative stress and hepatic cytokine (TNF- $\alpha$ and IL-6) response in the pathogenesis of hepatic collagenesis in chronic arsenic toxicity. Toxicol Appl Pharmacol 2005;204:18-26.

29. Thomas LB, Popper H, Berk PD, Selikoff I, Falk H. Vinyl-chlorideinduced liver disease. From idiopathic portal hypertension (Banti's syndrome) to angiosarcomas. N Engl J Med 1975;292:17-22.

30. Pimentel JC, Menezes AP. Liver disease in vineyard sprayers. Gastroenterology 1977;72:275-83.

31. Cortex Pimentel J, Peixoto Menezes A. Pulmonary and hepatic granulomatous disorders due to the inhalation of cement and mica dusts. Thorax 1978;33:219-27.

32. Podurgiel BJ, McGill DB, Ludwig J, Taylor WF, Muller SA. Liver injury associated with methotrexate therapy for psoriasis. Mayo Clin Proc 1973;48:787-92.

33. Geubel AP, De Galocsy C, Alves N, Rahier J, Dive C. Liver damage caused by therapeutic vit. A administration: estimate of dose related toxicity in 41 cases. Gastroenterology 1991;100: 1701-9.

34. Barnard JA, Marshall GS, Neblett WW, Gray G, Ghishan FK. Non-cirrhotic portal fibrosis after Wilms' tumor therapy. Gastroenterology 1986;90:1054-6.

35. Nayak NC. Pathology of non-cirrhotic portal fibrosis in India. In: Idiopathic Portal Hypertension, Okuda K, Omata M, eds. University of Tokyo Press: Tokyo 1983:37-47.

36. Aikat BK, Bhusnurmath SR, Chuttani PN, Mitra SK, Dutta DV. The pathology of non-cirrhotic portal fibrosis. Hum Pathol 1979;10: 405-18.

37. Tandon BN, Lakshminarayanan R, Bhargava S, Nayak NC, Sama SK. Ultrastructure of the liver in non-cirrhotic portal fibrosis with portal hypertension. Gut 1970;11:905-10.

38. Kumar A, Bhuyan UN, Nundy S. Glomerulonephritis complicating non-cirrhotic portal fibrosis. J Gastroenterol Hepatol 1998; 13(Suppl 1):271-5

39. Babbs C, Warnes TW, Haboubi NY. Non-cirrhotic portal hypertension with hypoxaemia. Gut 1998;29:129-31.

40. Matsutani S, Maruyama H, Akiike T, et al. Study of portal vein thrombosis in patients with idiopathic portal hypertension in Japan. Liver Int 2005;25:978-83.

41. Dhiman RK, Chawla Y, Vasishta RK, et al. Non-cirrhotic portal fibrosis (idiopathic portal hypertension): experience with 151 patients and a review of the literature. J Gastroenterol Hepatol 2002;17:6-16.

42. Bajaj JS, Bhattacharjee J, Sarin SK. Coagulation profile and platelet functions in patients with extrahepatic portal vein obstruction and non-cirrhotic portal fibrosis and influence of hypersplenism. J Gastroenterol Hepatol 2001;16:641-6.

43. Hillaire S, Bonte $\mathrm{E}$, Denninger $\mathrm{MH}$, et al. Idiopathic non-cirrhotic intrahepatic portal hypertension in the West: a re-evaluation in 28 patients. Gut 2002;51:275-80.

44. Ishii M, Katada Y. Idiopathic portal hypertension in a systemic sclerosis patient heterozygous for factor $\mathrm{V}$ Leiden mutation. Rheumatol Int 2003;23:44-6.

45. Bajaj JS, Bhattacharjee J, Sarin SK. Coagulation profile and platelet functions in patients with extrahepatic portal vein obstruction and non-cirrhotic portal fibrosis and influence of hypersplenism. J Gastroenterol Hepatol 2001;16:641-6.
46. Saito K, Nakanuma Y, Takegoshi K, et al. Non-specific immunological abnormalities and association of autoimmune diseases in idiopathic portal hypertension. A study by questionnaire. Hepatogastroenterology 1993;40:163-6.

47. Gürkaynak G, Yildirim B, Aksoy F, Temuçin G. Sonographic findings in noncirrhotic portal fibrosis. J Clin Ultrasound 1998;26: 309-13.

48. Sinha R. Grayscale and pulsed Doppler characteristics of noncirrhotic portal fibrosis: a preliminary report. Clin Radiol 1999 54:156-9.

49. Fukuda K, Kage M, Arakawa M, Nakashima T. Portal vein or hepatic vein? A curious aberrant vasculature in the liver with idiopathic portal hypertension. Acta Pathol Jpn 1985;35:885-97.

50. Dhiman RK, Behera A, Chawla YK, Dilawari JB, Suri S. Portal hypertensive biliopathy. Gut 2007;56:1001-8.

51. Chawla Y, Dilawari JB. Anorectal varices and their frequency in cirrhotic and non-cirrhotic portal hypertension. Gut 1991;32: 309-11.

52. Sarin SK, Govil A, Jain AK, et al. Prospective randomized trial of endoscopic sclerotherapy versus variceal band ligation for esophageal varices: influence on gastric varices and variceal recurrence. J Hepatol 1994;26:826-32.

53. Chawla YK, Dilawari JB, Dhiman RK, et al. Sclerotherapy in noncirrhotic portal fibrosis. Dig Dis Sci 1997;42:1449-53.

54. Bhargava DK, Dasarathy S, Sundaram KR, Ahuja RK. Efficacy of endoscopic sclerotherapy on long-term management of oesophageal varices: a comparative study of results in patients with cirrhosis of the liver, non-cirrhotic portal fibrosis (NCPF) and extrahepatic portal venous obstruction (EHO). J Gastroenterol Hepatol 1991; 6:471-5.

55. Kochhar R, Goenka MK, Mehta SK. Outcome of injection sclerotherapy using absolute alcohol in patients with cirrhosis, noncirrhotic portal fibrosis, and extrahepatic portal venous obstruction. Gastrointest Endosc 1991;37:460-4.

56. Kire CF. Controlled trial of propranolol to prevent recurrent variceal bleeding in patients with non-cirrhotic portal fibrosis. $\mathrm{Br} M e d$ 1989;298:1363-5.

57. Grace ND, Groszmann RJ, Garcia-Tsao G, Burroughs AK, Pagliaro L, Makuch RW. Portal hypertension and variceal bleeding: an AASLD single topic symposium. Hepatology 1998;28:868-80.

58. Sarin SK, Jain AK, Jain M, et al. A randomized controlled trial of cyanoacrylate versus alcohol injection in patients with isolated fundic varices. Am J Gastroenterol 2002;97:1010-5.

59. Dhiman RK, Chawla Y, Taneja S, Biswas R, Sharma TR, Dilawari JB. Endoscopic sclerotherapy of gastric variceal bleeding with N-butyl-2-cyanoacrylate. J Clin Gastroenterol 2002;35:222-7.

60. Hirota S, Ichikawa S, Matsumoto S, et al. Interventional radiologic treatment of idiopathic portal hypertension. Cardiovasc Intervent Radiol 1999;22:311-4.

61. Mitra SK, Rao KL, Narasimhan KL, et al. Side-to-side lienorena shunt without splenectomy in non-cirrhotic portal hypertension in children. J Pediatr Surg 1993;28:398-401.

62. Warren WD, Henderson JM, Millikan WJ, et al. Management of variceal bleeding in patients with noncirrhotic portal vein throm bosis. Ann Surg 1988;207:623-34

63. Sarin SK, Kapoor D. Non-cirrhotic portal fibrosis: current concepts and management. J Gastroenterol Hepatol 2002;17: 526-34.

64. Sharma BC, Singh RP, Chawla YK, Narasimhan KL, Rao KL, Mitra SK. Effect of shunt surgery on spleen size, portal pressure and esophageal varices in noncirrhotic portal fibrosis. J Gastroenterol Hepatol 1997;12:582-4.

65. Sarin SK, Kumar A. Non-cirrhotic portal hypertension. Clin Liver Dis 2006;10:627-51.

66. Sarin SK, Agarwal SR. Extrahepatic portal vein obstruction. Semin Liver Dis 2002;22:43-58. 


\section{JOURNAL OF CLINICAL AND EXPERIMENTAL HEPATOLOGY}

67. Tizard JPM. Portal hypertension following exchange transfusion through the umbilical vein. Proc $R$ Soc Med 1962;55:772-9.

68. Shaldon S, Sherlock S. Obstruction to the extrahepatic portal system in childhood. Lancet 1962;1:63-7.

69. Yachha SK, Aggarwal R, Sharma BK, et al. Functional protein C and anticardiolipin antibodies in children with portal vein thrombosis. Ind J Gastro 2001;20:47-9.

70. Primignani M, Martinelli I, Bucciarelli P, et al. Risk factors for thrombophilia in extrahepatic portal vein obstruction. Hepatology 2005;41:603-8.

71. Cardin F, Graffeo M, McCormick PA, et al. Adult "ideopathic" extrahepatic venous thrombosis. Importance of putative "latent" myeloproliferative disorders and comparison with cases with known etiology. Dig Dis Sci 1992;37:335-9.

72. Winslow ER, Brunt LM, Drebin JA, et al. Portal vein thrombosis after splenectomy. Am J Surg 2002;184:631-5. [Discussion 635-6.]

73. Habu D, Nishiguchi S, Shiomi S, et al. Portal vein thrombosis following percutaneous ethanol injection therapy for hepatocellular carcinoma. Ind J Gastroenterol 2002;21:162-3.

74. Matsumoto K, Yamao K, Ohashi K, et al. Acute portal vein thrombosis after EUS-guided FNA of pancreatic cancer: case report. Gastrointest Endosc 2003;57:269-71.

75. Webb LJ, Sherlock S. The aetiology, presentation and natural history of extra-hepatic portal venous obstruction. Q J Med 1979; 192:627-39.

76. Boles ET, Wise WE, Birken G. Extrahepatic portal hypertension in children. Long-term evaluation. Am J Surg 1986;151:734-9.

77. Voigt MD, Trey G, Levitt NS, et al. Autonomic neuropathy in extrahepatic portal vein thrombosis: evidence for impaired autonomic reflex arc. J Hepatol 1997;26:634-41.

78. Dhiman RK, Puri P, Chawla Y, et al. Biliary changes in extrahepatic portal venous obstruction: compression by collaterals or ischemic? Gastrointest Endosc 1999;50:646-52.

79. Mehrotra RN, Bhatia V, Dabadghao P, et al. Extrahepatic portal vein obstruction in children: anthropometry, growth hormone, and insulin-like growth factor 1. J Pediatr Gastroenterol Nutr 1997; 25:520-3.

80. Kato T, Romero R, Koutouby R, et al. Portosystemic shunting in children during the era of endoscopic therapy: improved postoperative growth parameters. J Pediatr Gastroenterol Nutr 2000; 30:419-25.

81. Poddar U, Thapa BR, Singh K. Band ligation plus sclerotherapy versus sclerotherapy alone in children with extrahepatic portal venous obstruction. J Clin Gastroenterol 2005;39:626-9.

82. Orloff MJ, Orloff MS, Girard B, et al. Bleeding esophago-gastric varices from extrahepatic portal hypertension. 40 year experience with portal systemic shunt. J Am Coll Surg 2002;194:717-28.

83. Superina R, Shneider B, Emre S, Sarin S, de Ville de Goyet J. Surgical guidelines for the management of extra-hepatic portal vein obstruction. Pediatr Transplant 2006;10:908-13.

84. Sharma M, Pathak A. Intracholedochal varices in portal hypertensive biliopathy. Eur J Radiol Extra 2009;72:e119-23.

85. Dhiman RK, Behera A, Chawla YK, Dilawari JB, Suri S. Portal hypertensive biliopathy. Gut 2007;56:1001-8.

86. Chawla Y, Duseja A, Dhiman RK. Review article: the modern management of portal vein thrombosis. Aliment Pharmacol Ther 2009;30:881-94.

87. Adel AF Mahmoud. Schistosomiasis and other trematode infections. Harrison's Principles of Internal Medicine 17th ed., 1499503.

88. Andrade ZA. Schistosomal hepatopathy. Mem Inst Oswaldo Cruz 2004;99(5 Suppl 1):51-7.

89. Carruthers RH, Sinha P. Bilharzial portal fibrosis: an important cause of portal hypertension. Ann R Coll Surg Engl 1978;60: 49-52.
90. Dessein AJ, Hillaire D, Elwali NE, et al. Severe hepatic fibrosis in Schistosoma mansoni infection is controlled by a major locus that is closely linked to the interferon-gamma receptor gene. Am J Hum Genet 1999;65:709-21.

91. Coelho RB. Lesões hepáticas secundárias. In: Anatomiapatológica das afecções hepáticas. Recife: Editora da UFPE, Coelho RB 1971:59-77.

92. De Cock KM. Hepatosplenic schistosomiasis: a clinical review. Gut 1986;27:734-45.

93. Stuiver PC. Acute schistosomiasis (Katayama fever). Br Med J 1984;288:221-2.

94. Coutinho A. Hemodynamic studies of portal hypertension in schistosomiasis. Am J Med 1968;4:547-56.

95. Andrade ZA, Santana Filho S, Rubim E. Hepatic changes in advanced schistosomiasis. Gastroenterology 1962;42:393-400.

96. Cheever AW, Andrade ZA. Alterations of the intrahepatic vasculature in hepatosplenic schistosomiasis mansoni. Am J Trop Med Hyg 1971;20:425-32.

97. De Cock KM. Splenomegaly and portal hypertension in Nairobi, Kenya: a study in geographical medicine. University of Bristol, MD Thesis, 1983.

98. Jordan P. Diagnostic and laboratory techniques. In: Schistosomiasis. Epidemiology, Treatment and Control, Jordan P, Webbe G, eds. Heinemann: London 1982:165-83.

99. Smithers SR, Doenhoff MJ. Schistosomiasis. In: Immunology of Parasitic Infections, Cohen S, Warren KS, eds. Blackwell: Oxford 1982:527-607.

100. Dusek J, Kubasta M, Kodousek R, Kubastova B. Needle biopsy of the liver in schistosomiasis mansoni: the value of histological examination. J Trop Med Hyg 1965;68:189-95.

101. De Cock KM. Human schistosomiasis and its management. J Infect 1984;8:5-12.

102. Mutapi F, Ndhlovu PD, Hagan P, et al. Chemotherapy accelerates the development of acquired immune responses to Schistosoma haematobium infection. J Infect Dis 1998;178:289-93.

103. Siqueira ES, Rohr MR, Libera ED, Castro RR, Ferrari AP. Band ligation or sclerotherapy as endoscopic treatment for oesophageal varices in schistosomotic patients: results of a randomized study. HPB Surg 1998;11:27-32.

104. el Tourabi H, el Amin AA, Shaheen M, Woda SA, Homeida M, Harron DW. Propranolol reduces mortality in patients with portal hypertension secondary to schistosomiasis. Ann Trop Med Parasitol 1994;88:493-500.

105. da Silva LC, Strauss E, Gayotto LC, et al. A randomized trial for the study of the elective surgical treatment of portal hypertension in mansonic schistosomiasis. Ann Surg 1986;204: 148-53.

106. Ezzat FA, Abu-Elmagd KM, Aly MA, et al. Selective shunt versus nonshunt surgery for management of both schistosomal and nonschistosomal variceal bleeders. Ann Surg 1990;212:97-108.

107. Shorbagi A, Bayraktar Y. Experience of a single center with congenital hepatic fibrosis: a review of the literature. World $J$ Gastroenterol 2010;16:683-90.

108. Zeitoun D, Brancatelli G, Colombat M, Vilgrain V, et al. Congenital hepatic fibrosis: CT findings in 18 adults. Radiology 2004; 231:109-16.

109. Akhan O, Karaosmanoglu AD, Ergen B. Imaging findings in congenital hepatic fibrosis. Eur J Radiol 2007;61:18-24.

110. Di Bisceglie AM, Befeler AS. Cystic and nodular diseases on the liver. In: Schiff's Diseases of the Liver 10th ed. Lippincott Williams \& Wilkins: PA 2007:1231-51.

111. Kerr DN, Okonkwo S, Choa RG. Congenital hepatic fibrosis: the longterm prognosis. Gut 1978;19:514-20.

112. Stromeyer FW, Ishak KG. Nodular transformation (nodular "regenerative" hyperplasia) of the liver. A clinicopathologic study of 30 cases. Hum Pathol 1981;12:60-71. 
113. Naber AH, Van Haelst U, Yap SH. Nodular regenerative hyperplasia of the liver: an important cause of portal hypertension in non-cirrhotic patients. J Hepatol 1991;12:94-9.

114. Wanless IR. Micronodular transformation (NRH) of the liver: a report of 64 cases among 2,500 autopsies and a new classification of benign hepatocellular nodules. Hepatology 1990;11:787-97.

115. Nzeako UC, Goodman ZD, Ishak KG. Hepatocellular carcinoma and nodular regenerative hyperplasia; possible pathogenetic relationship. Am J Gastroenterol 1996;91:879-84.

116. Wanless IR, Godwin TA, Allen F, Feder A. Nodular regenerative hyperplasia of the liver in hematologic disorders: a possible response to obliterative portal venopathy. A morphometric study of nine cases with an hypothesis on the pathogenesis. Medicine (Baltimore) 1980;59:367-79.

117. Qizilbash AH, Castelli M. Nodular regenerative hyperplasia of the liver: diagnosis by liver biopsy. Can Med Assoc J 1980;122:1151-4.

118. Kingham JGC, Levison DA, Stansfield AG, Dawson AM. Noncirrhotic idiopathic portal hypertension: a long term follow up study. Q J Med 1981;199:259-68.

119. Rougier P, Degott C, Rueff B, Benhamou JP. Nodular regenerative hyperplasia of the liver. Gastroenterology 1978;75:169-72.

120. Guarda LA, Hales MR. Nodular regenerative hyperplasia of the liver: report of two cases and review of the literature. J Clin Gastroenterol 1981;3:157-64.

121. Ludwig J, Hashimoto E, McGill DB, van Heerden JA. Classification of hepatic venous outflow obstruction: ambiguous terminology of the Budd-Chiari syndrome. Mayo Clin Proc 1990;65:51-5.

122. DeLeve LD, Shulman HM, McDonald GB. Toxic injury to hepatic sinusoids: sinusoidal obstruction syndrome (veno-occlusive disease). Semin Liver Dis 2002;22:27-42.

123. Janssen HL, Meinardi JR, van Der Meer FJ, et al. Factor V Leiden mutation, prothrombin gene mutation, and deficiencies in coagulation inhibitors associated with Budd-Chiari syndrome and portal vein thrombosis: results of a case-control study. Blood 2000;96:2364-8.

124. Murad SD, Plessier A, Hernandez-Guerra M, et al. Prospective follow-up study on 163 patients with Budd-Chiari syndrome: results from the European network for vascular disorders of the liver (EN-VIE). J Hepatol 2007;46:S4.

125. Dilawari JB, Bambery P, Chawla Y, et al. Hepatic outflow obstruction (Budd-Chiari syndrome). Experience with 177 patients and a review of the literature. Medicine (Baltimore) 1994;73:21-36.

126. Valla DC. Hepatic vein thrombosis (Budd-Chiari syndrome). Semin Liver Dis 2002;22:5-14.

127. Hadengue A, Poliquin M, Vilgrain V, et al. The changing scene of hepatic vein thrombosis: recognition of asymptomatic cases. Gastroenterology 1994;106:1042-7.

128. Langlet $P$, Escolano S, Valla D, et al. Clinicopathological forms and prognostic index in Budd-Chiari syndrome. $J$ Hepatol 2003; 39:496-501.

129. Gupta S, Barter S, Phillips GW, Gibson RN, Hodgson HJ. Comparison of ultrasonography, computed tomography and $99 m$ Tc liver scan in diagnosis of Budd-Chiari syndrome. Gut 1987;28:242-7.

130. Hoekstra J, Janssen HL. Vascular liver disorders (I): diagnosis, treatment and prognosis of Budd-Chiari syndrome. Neth J Med 2008;66:334-9.

131. Ringe $\mathrm{B}$, Lang $\mathrm{H}$, Oldhafer $\mathrm{KJ}$, et al. Which is the best surgery for Budd-Chiari syndrome: venous decompression or liver transplantation? A single-center experience with 50 patients. Hepatology 1995;21:1337-44.

132. Raju GS, Felver M, Olin JW, Satti SD. Thrombolysis for acute Budd-Chiari syndrome: case report and literature review. Am J Gastroenterol 1996;91:1262-3.

133. Bilbao JI, Pueyo JC, Longo JM, et al. Interventional therapeutic techniques in Budd-Chiari syndrome. Cardiovasc Intervent Radio 1997;20:112-9.

134. Molmenti EP, Segev DL, Arepally A, et al. The utility of TIPS in the management of Budd-Chiari syndrome. Ann Surg 2005;241: 978-81. [Discussion 982-3.]

135. Richardson P, Guinan E. The pathology, diagnosis, and treat ment of hepatic veno-occlusive disease: current status and novel approaches. Br J Haematol 1999;107:485-93.

136. Bras G, Jaliffe DB, Stuart KL. Veno-occlusive disease of the liver with non-portal type of cirrhosis occurring in Jamaica. Arch Pathol 1954;87:285-300.

137. Carreras E, Bertz H, Arcese W, et al. Incidence and outcome of hepatic veno-occlusive disease after blood or marrow transplantation: a prospective cohort study of the European Group for Blood and Marrow Transplantation. Blood 1998;92:3599-604.

138. Sebagh M, Debette M, Samuel D, et al. "Silent” presentation of veno-occlusive disease after liver transplantation as part of the process of cellular rejection with endothelial predilection. Hepatology 1999;30:1144-50.

139. Jones RJ, Lee KS, Beschorner WE, et al. Veno-occlusive disease of the liver following bone marrow transplantation. Transplantation 1987;44:778-83.

140. Senzolo M, Germani G, Cholongitas E, Burra P, Burroughs AK. Veno-occlusive disease: update on clinical management. World J Gastroenterol 2007;13:3918-24.

141. Toh HC, McAfee SL, Sackstein R, Cox BF, Colby C, Spitzer TR. Late onset veno-occlusive disease following high-dose chemotherapy and stem cell transplantation. Bone Marrow Transplant 1999;24:891-5.

142. Ben-Ari Z. Ascites after transplantation-a mystery. Liver Transpl 2004;10:1221.

143. Petaja J, Pitkanen S, Vettenranta K, Fasth A, Heikinheimo M. Serum tumor marker CA 125 is an early and sensitive indicator of veno-occlusive disease in children undergoing bone marrow transplantation. Clin Cancer Res 2000;6:531-5.

144. Helmy A. Review article: updates in the pathogenesis and therapy of hepatic sinusoidal obstruction syndrome. Aliment Pharmacol Ther 2006;23:11-25.

145. Lassau N, Auperin A, Leclere J, Bennaceur A, Valteau-Couanet D, Hartmann O. Prognostic value of Doppler-ultrasonography in hepatic veno-occlusive disease. Transplantation 2002;74:60-6.

146. Shulman HM, Gooley T, Dudley MD, et al. Utility of transvenous liver biopsies and wedged hepatic venous pressure measurements in sixty marrow transplant recipients. Transplantation 1995;59:1015-22.

147. Bearman SI, Anderson GL, Mori M, Hinds MS, Shulman HM, McDonald GB. Veno-occlusive disease of the liver: development of a model for predicting fatal outcome after marrow transplantation. J Clin Oncol 1993;11:1729-36

148. The WT, Beyer W, Pendleton JD. Genetic polymorphisms in glutathione S-transferase and plasminogen activator inhibitor and risk of veno-occlusive disease (VOD). Blood 2000;96:390A. [Abstract]. 